\title{
Neurological Complications of Solid Organ Transplantation
}

\author{
The Neurohospitalist \\ 3(3) I52-166 \\ (C) The Author(s) 2012 \\ Reprints and permission: \\ sagepub.com/journalsPermissions.nav \\ DOI: 10.1 | $77 / 19418744 \mid 2466090$ \\ nhos.sagepub.com
}

(SSAGE

\author{
Amy A. Pruitt, MD', Francesc Graus, MD $^{2}$, and \\ Myrna R. Rosenfeld, MD, PhD'
}

\begin{abstract}
Solid organ transplantation (SOT) is the preferred treatment for an expanding range of conditions whose successful therapy has produced a growing population of chronically immunosuppressed patients with potential neurological problems. While the spectrum of neurological complications varies with the type of organ transplanted, the indication for the procedure, and the intensity of long-term required immunosuppression, major neurological complications occur with all SOT types. The second part of this 2-part article on transplantation neurology reviews central and peripheral nervous system problems associated with SOT with clinical and neuroimaging examples from the authors' institutional experience. Particular emphasis is given to conditions acquired from the donated organ or tissue, problems specific to types of organs transplanted and drug therapy-related complications likely to be encountered by hospitalists. Neurologically important syndromes such as immune reconstitution inflammatory syndrome (IRIS), posterior reversible encephalopathy syndrome (PRES), and posttransplantation lymphoproliferative disorder (PTLD) are readdressed in the context of SOT.
\end{abstract}

\section{Keywords}

hepatic encephalopathy, immune reconstitution inflammatory syndrome, organ transplantation, posterior reversible encephalopathy syndrome, posttransplantation lymphoproliferative disorder, progressive multifocal leukoencephalopathy, toxoplasmosis

\section{Procedures and Terminology}

Solid organ transplantation (SOT) refers to the receipt of an entire organ such as heart, lung, liver, pancreas, or kidney from tissue-matched deceased donors or to receipt of kidney or partial liver or intestinal tissue from a recipient-related or matched unrelated living donor.

\section{Potential Problems Common to all SOT Recipients}

SOT patients received 28535 heart, lung, liver, kidney, pancreas, or small intestine transplantations in 2011 in the United States. ${ }^{1}$ Approximately one-third of SOT patients will experience a neurological complication. ${ }^{2}$ Neurological complications common to all SOT not caused by transplanted organ failure are frequently attributable to immunosuppressive regimens. Common neurological complications are seizures, central nervous system (CNS) infections, encephalopathy, and stroke. ${ }^{2,3}$

Few neurologic complications occur exclusively in a specific transplant population, but both in the early days and throughout their posttransplantation course, recipients of different tissues and organs have predictably varied complication patterns. For example, hematopoietic stem cell transplantation (HCT) is more frequently done for malignancy than is SOT, and posttransplantation HCT patients may be more acutely ill more often pancytopenic and at greater long-term risk of disease recurrence. ${ }^{2-4}$

Among SOT recipients, liver transplant recipients, particularly those with fulminant hepatic failure and coagulopathy, have the most serious medical problems at the time of their transplant with concomitantly more early complications. ${ }^{3}$ Months to years after SOT, complication profiles reflect the degree and duration of immunosuppression necessary to prevent rejection. Thus, heart and intestinal/pancreas recipients, the most heavily chronically immunosuppressed groups, are most prone to late infectious complications. ${ }^{3}$ Table 1 provides

\footnotetext{
' Department of Neurology, University of Pennsylvania, Philadelphia, PA, USA

${ }^{2}$ Neurology Service and Institut de Recerca Biomèdica August Pi I Sunyer, Barcelona, Spain

Corresponding Author:

Amy A. Pruitt, Department of Neurology, University of Pennsylvania, 3400 Spruce St, Philadelphia PA 19104, USA.

Email: pruitt@mail.med.upenn.edu
} 
Table I. Comparative Urgent Transplantation Conditions for the Neurohospitalist.

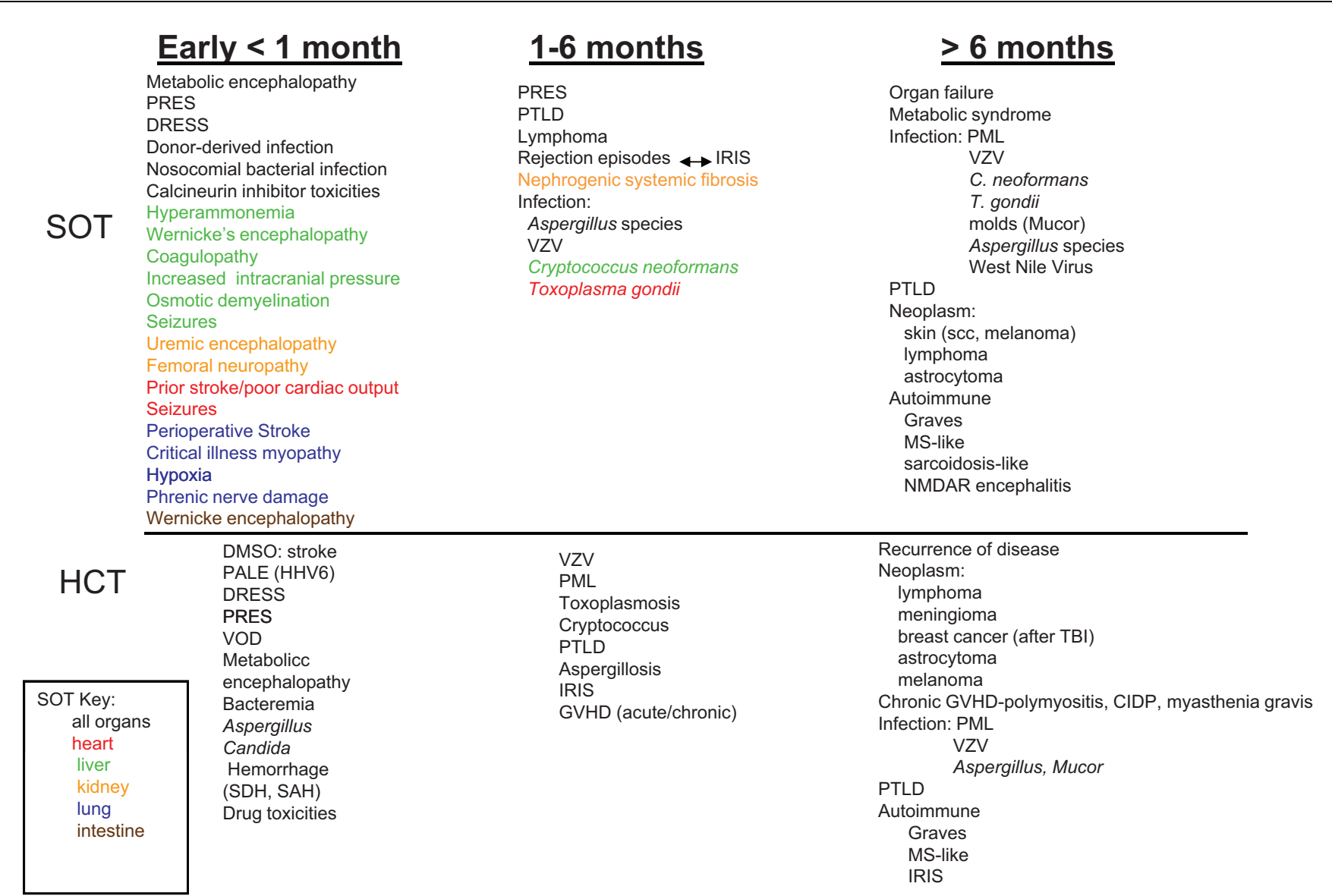

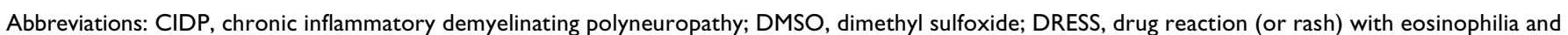

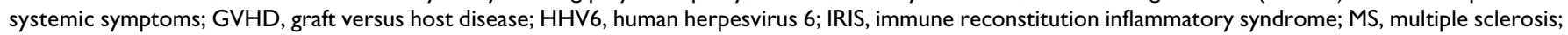

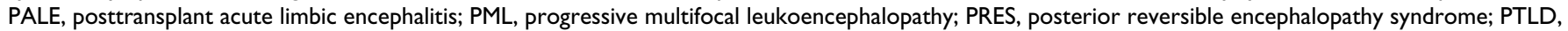

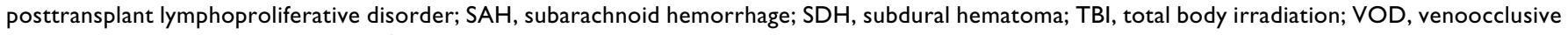
disease; VZV, varicella-zoster virus; HCT, hematopoietic stem cell transplantation.

a framework for consultation by contrasting neurological complications encountered at various intervals after SOT with the somewhat different diagnostic issues confronted by neurologists evaluating HCT patients.

\section{Encephalopathy}

Pretransplant cognitive dysfunction is present in many patients, particularly those with end-stage renal disease or liver failure for whom severity of hepatic encephalopathy is a criterion for organ transplantation. ${ }^{4}$ Acknowledging that algorithms are hazardous when applied to complicated patients with multiple medical problems, we provide in Table 2 a general consultative scheme to evaluate encephalopathy in an SOT recipient. After physical examination, investigation usually includes early neuroimaging, preferably magnetic resonance imaging (MRI) with gadolinium contrast, if glomerular filtration rate exceeds $30 \mathrm{~mL} / \mathrm{min}$.
The MRI may be normal or nonspecifically abnormal in many metabolic encephalopathies, but other encephalopathies show characteristic abnormalities that may guide clinical weighting of potential causes of altered mental status. ${ }^{5}$ For example, hyperammonemic encephalopathy produces signal change in the insular and cingulate cortices with relative sparing of the perirolandic and occipital cortices (Figure $1 \mathrm{~A}$ and B). ${ }^{6}$ In addition, unusual severity of a presumed drug adverse effect such as severe tremor on tacrolimus may be explained by antecedent structural changes revealed by MRI. An example is illustrated in Figure $1 \mathrm{C}$ and $\mathrm{D}$ in a patient with preexisting liver failure-related globus pallidus abnormalities.

\section{Posterior Reversible Encephalopathy Syndrome}

A special subcategory of encephalopathy in organ transplant recipients is posterior reversible encephalopathy syndrome 
Table 2. Neurologic Consultation: The Encephalopathic Solid Organ Transplant Recipient.

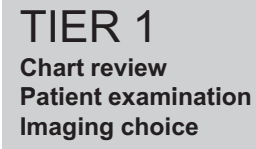

\section{TIER 2} High priority History and Physical Exam screens for most patients

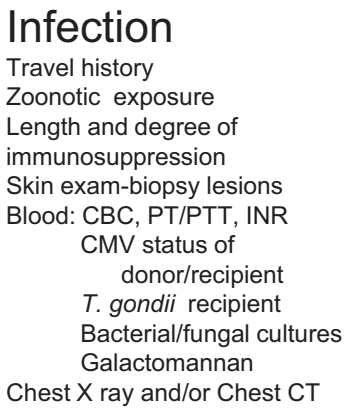

Metabolic
Renal function
Hepatic function panel
NH3
ABGs
Lactate/pyruvate
Electrolytes: Osmotic demyelination?
Wernicke's possible?

\author{
Drug Toxicities \\ Calcineurin inhibitor level \\ PRES \\ Mycophenolate \\ PML \\ Rituximab \\ PML \\ Toxic screen \\ Cefepime \\ PRES \\ DRESS
}

TIER 3
Extended workup
for selected
patients, e.g.
Focal signs,
Coagulopathy

$\begin{aligned} \begin{array}{ll}\text { Infection } \\ \text { Galactomannan index } \\ \text { bronchoalveolar lavage }\end{array} & \begin{array}{l}\text { Vascular } \\ \text { Consider: }\end{array} \\ \begin{array}{c}\text { CSF: pcrb } \text { HSV1,2,6,7 } \\ \text { VZV CMV,EBV, }\end{array} & \text { CHF } \\ \text { JCV,WNV } & \text { Arrhythmia } \\ \text { Cryptococcal } & \text { Endocarditis } \\ \text { antigen } & \text { Vasculitis (VZV) } \\ \text { Galactomannan } & \text { DIC } \\ \text { Antibodies: IgM } & \text { HIT } \\ \text { WNV IG G VZV,IgG } & \text { Cerebral venous thrombosis } \\ \text { HSV1 } & \text { MRA/MRVICTA } \\ \text { Stool culture (C. difficile, } & \text { Angiogram } \\ \text { parasites) } & \end{aligned}$

TIER 4: Less common syndromes and situations

Occult/Recurrent
Malignancy
CSF cytology/flow cytometery
IgH heavy chain
rearrangement
PTLD: ophthalmology exam,
Primary or secondary brain
$\quad$ tumor- consider biopsy
SPEP/UPEP
Paraneoplastic panel
Body PET

Immune Dysregulation Organ rejection IRIS Sarcoidosis Multiple sclerosis-like tibodies: IgM HSV

\footnotetext{
${ }^{a}$ MRI with gadolinium if glomerular filtration rate (GFR) $>30$.

${ }^{b}$ Or antibody based on timing-DNA-based tests in first few days after symptom onset with antibodies more useful after 7 to 10 days. Abbreviations: CMV, cytomegalovirus; DIC, disseminated intravascular coagulation; DRESS, drug reaction (rash) with eosinophilia and systemic symptoms; FIRDA, frontal intermittent rhythmic delta activity; HIT, heparin-associated immune thrombocytopenia; HSV, herpes simplex virus; IRIS, immune reconstitution inflammatory syndrome; PLEDS, periodic lateralized epileptiform discharges; PRES, posterior reversible encephalopathy syndrome; PTLD, posttransplant lymphoproliferative disorder; EBV, Epstein-Barr virus; WNV, West Nile virus; VZV, varicella-zoster virus; MRI, magnetic resonance imaging; Ig, immunoglobulin; $C$ difficile, Clostridium difficile; $T$ gondii, Toxoplasma gondii.
}

(PRES) or reversible posterior leukoencephalopathy syndrome (RPLS). In part I of this review, a detailed discussion of PRES is accompanied by common and atypical MRI examples. The condition usually presents with a combination of headache, confusion, seizures, and blood pressure elevation. The MRI classically shows posterior hemisphere predominant abnormalities consistent with vasogenic edema. Rare biopsies of this condition (done because of diagnostic uncertainty with atypical MRI, persistent seizure activity, or concern for infection) have revealed white matter edema without evidence of infarction or fibrinoid necrosis. ${ }^{7}$ Thus, the pathophysiology is distinct from that of malignant hypertension and some studies suggest that vascular endothelial growth factor activation plays a pathogenic role. ${ }^{8}$ While PRES is often reversible, it can be associated with stroke and recurrent seizures. Figure 2 illustrates what might be called PRES plus in a liver transplant recipient whose PRES was complicated by vasculopathy and stroke. When PRES develops during treatment with either tacrolimus or cyclosporine, it is reasonable to substitute the alternative calcineurin inhibitor or sirolimus, everolimus, or mycophenolate.

\section{Infections}

Donor organs. In addition to community-acquired infections or nosocomial complications such as intravenous line infections or ventilator-associated pulmonary infection, SOT patients are at risk for infections associated with the donor organ. Four fatal cases of human-to-human rabies transmission via liver, kidney, and arterial allograft occurred after all had received tissue from a single donor. The door's death was attributed to subarachnoid hemorrhage with ballistic 


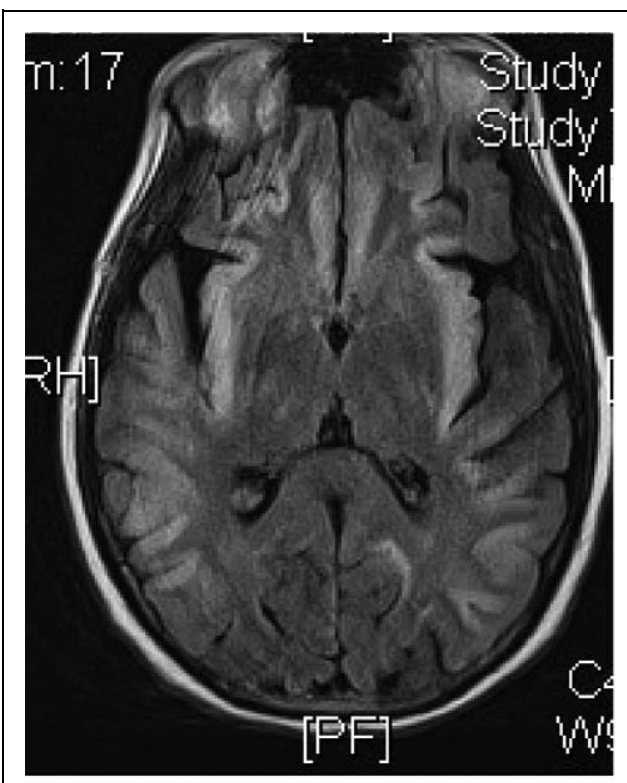

A

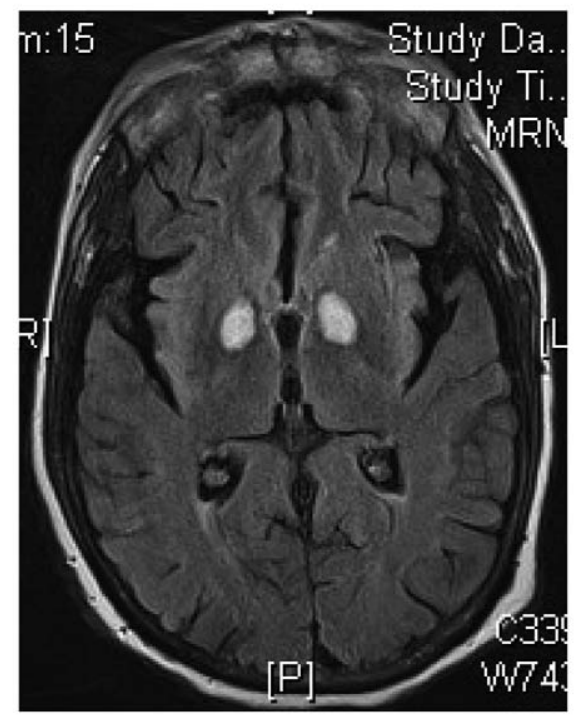

C

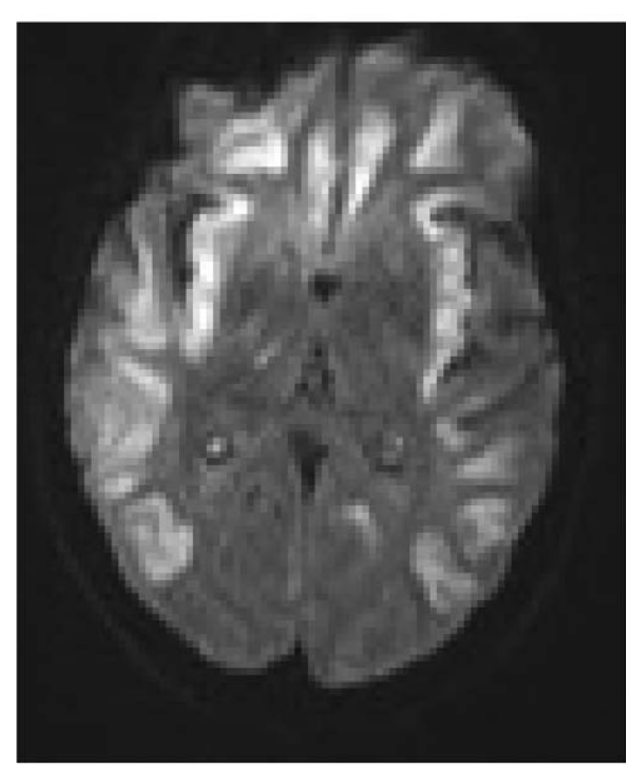

B

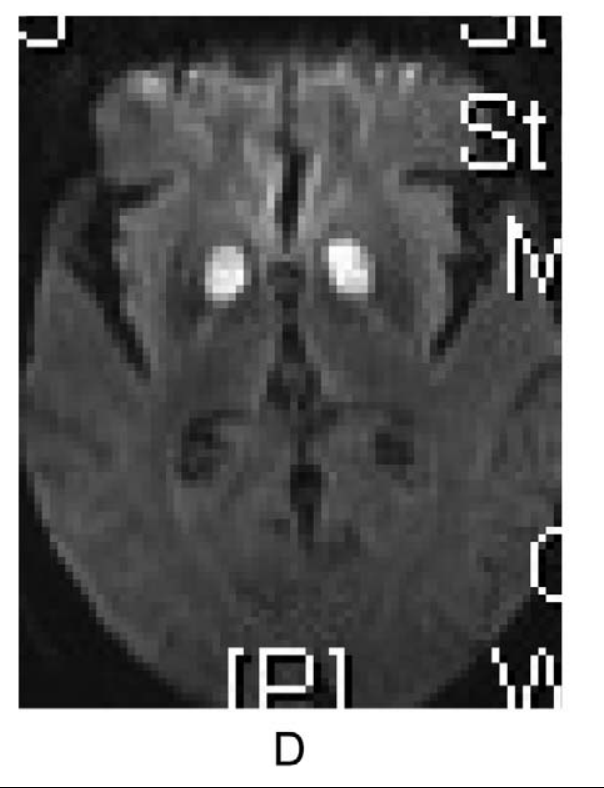

Figure I. Liver transplant-related encephalopathies. Patient I (A and B) with hyperammonemic encephalopathy has distinct FLAIR (A) and DWI (B) cortical abnormalities sparing occipital cortex. Patient 2 ( $C$ and D) was imaged 2 weeks after liver transplant for alcoholic cirrhosis. Patient 2 had a slight tremor pretransplant that became disabling on tacrolimus. The MRI shows hyperintense lesions on FLAIR (C) and DWI (D) involving the globus pallidus. These were seen on a preoperative CT (not shown) and were thought to represent hepatocerebral degeneration. FLAIR indicates fluid attenuated inversion recovery; DWI, diffusion-weighted imaging; CT, computed tomography.

movements caused by cocaine. ${ }^{9}$ Donor-transmitted lymphocytic choriomeningitis virus (LCMV), West Nile virus (WNV), and amebic (Balamuthia mandrillaris) encephalitis have also been reported (Figure 3 ). ${ }^{10-14}$ Cryptococcosis can be transmitted by organ donation in which case it may be found in unusual locations near the transplanted organ site. ${ }^{15,16}$ Failure to suspect infection in donors with premorbid encephalitic symptoms led to death of most immunosuppressed recipients. Subarachnoid hemorrhage or acute disseminated encephalomyelitis were frequent donor misdiagnoses, emphasizing the critical need for neurological diagnostic input in assessing donor as well as recipient medical histories. Serologic screening standards for allograft donors are not uniform and antibody-based assays may be negative early after initial infection (in the so-called window period). For this reason, donor screening by nucleic acid-based testing (polymerase chain reaction [PCR]) may be more accurate during acute infection. ${ }^{17}$ Consideration of the geographic origin 


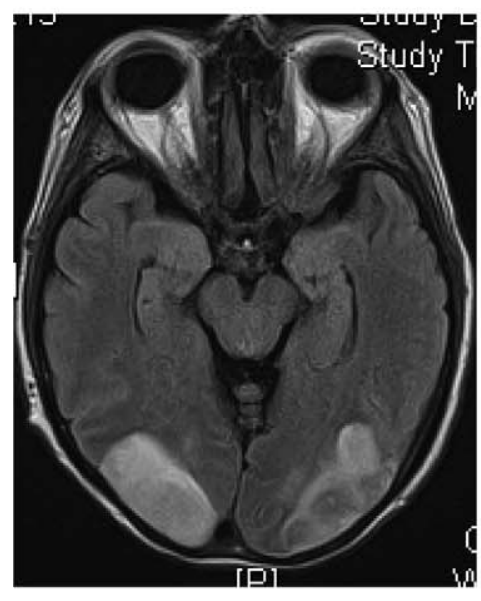

A

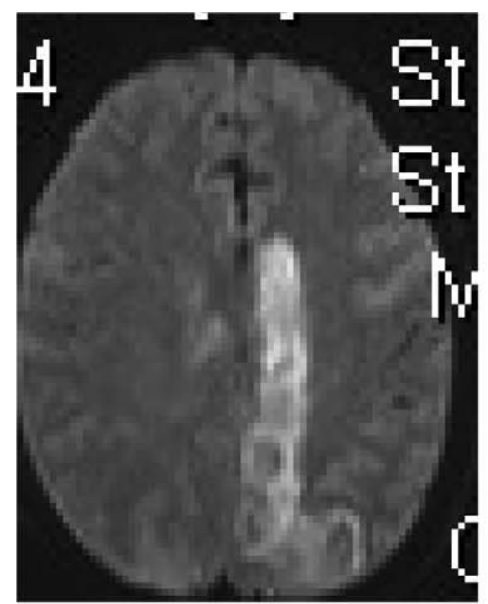

B

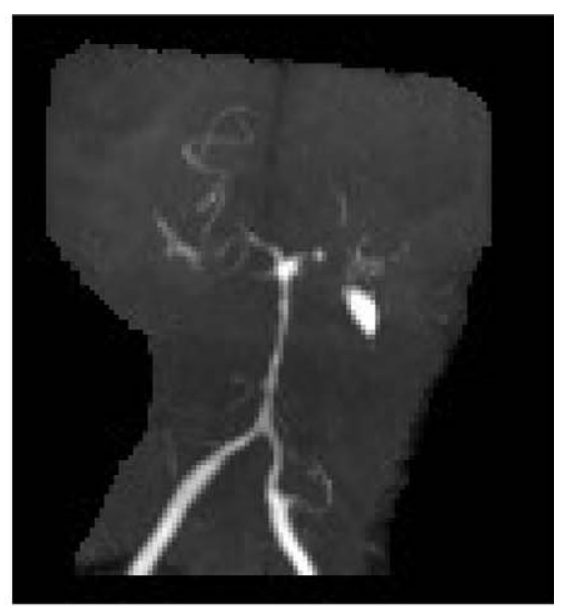

C

Figure 2. FLAIR MRI (A) of patient 2 weeks after liver transplant with evidence of PRES and also subacute infarction on diffusion-weighted imaging (B) with diffuse narrowing of proximal vertebral and basilar arteries indicative of vasculopathy on MRA (C). FLAIR indicates fluid attenuated inversion recovery; MRI, magnetic resonance imaging; MRA, magnetic resonance angiography.

of donor and recipient may provide useful clues as demonstrated by the recent report of human T-lymphotrophic virus (HTLV1)associated myelopathy emerging in a patient from an endemic region, who received a liver donation from his living sister. ${ }^{18}$

Drug regimen and infection risk. Several medicines administered for induction therapy, infection prophylaxis, and rejection treatment are associated with special profiles of infection risk. Alemtuzumab, a humanized monoclonal antibody against the CD-52 glycoprotein on both $\mathrm{B}$ and $\mathrm{T}$ lymphocytes and natural killer cells, is associated with increased risk of invasive fungal infections when given to treat allograft rejection and less frequently when it is part of the induction regimen. ${ }^{19,20}$ Mycophenolate mofetil (MMF) or low-dose rituximab induction therapy both increase the risk of cytomegalovirus (CMV) reactivation. ${ }^{21-23}$

Patients remain at risk for opportunistic infections for years after their SOT. It is in this latter period that progressive multifocal leukoencephalopathy (PML) remains a relevant concern. PML has been reported 10 years post orthotopic liver transplantation (OLT) ${ }^{24}$ In a large case series from 4 academic medical centers, the median time to development of first PML symptoms was longer in SOT versus HCT transplants (27 vs 11 months) and median survival was shorter among SOT recipients (6.4 months vs 19.5 months in HCT recipients). ${ }^{25} \mathrm{~A}$ special risk factor in SOT recipients appears to be conversion from cyclosporine or tacrolimus to mycophenolate mofetil. ${ }^{26-28}$

Cryptococcus neoformans. Despite advances in antimicrobial prophylaxis in SOT, the incidence of cryptococcosis has remained unchanged over the past 20 years, with an overall incidence of $2.8 \%$ and CNS involvement in $53 \%$ to $72 \%$ of these. ${ }^{29,30}$ Overall mortality in the modern era remains $15 \%$ to $20 \% .{ }^{31}$ Patients with end-stage liver disease are at particular risk even before transplantation due to impaired cell-mediated immunity, and the prognosis in this patient group is particularly poor. Guidelines for fungicidal therapy when CNS involvement is present call for a lipid formulation of amphotericin-B and 5-flucytosine. ${ }^{32}$ The timing of transplantation with respect to treatment of preexisting cryptococcosis remains problematic. Posttransplant it is suggested that organ rejection be prevented with a regimen of tacrolimus or cyclosporine due to demonstrated in vitro activity of the calcineurin inhibitor class of drugs against cryptoccocus. ${ }^{33,34}$ Avoiding both alemtuzumab and antithymocyte globulin due to their association with increased risk of cryptococcosis is advisable. ${ }^{35}$

\section{Immune Reconstitution Inflammatory Syndrome (IRIS) in SOT}

Cryptococcal infection discussed above serves as the prototype of the general problem of balancing infection control and inflammatory response in SOT recipients. On first consideration, reduction of immunosuppression in transplant recipients with opportunistic infections would seem a logical strategy. However, rapid reduction of immunosuppression in conjunction with antifungal or other antimicrobial therapy may lead to a dangerous proinflammatory response. While contributing to infection control, the inflammation may be detrimental to the host and may predispose to allograft rejection. First recognized in the HIV population during highly active antiretroviral therapy (HAART), IRIS is defined as a deterioration in clinical status due to an intense inflammatory response resulting from recovery of the immune system. ${ }^{35}$ It is being recognized with increasing frequency in $\mathrm{HCT}$ and SOT transplant recipients after reduction in 

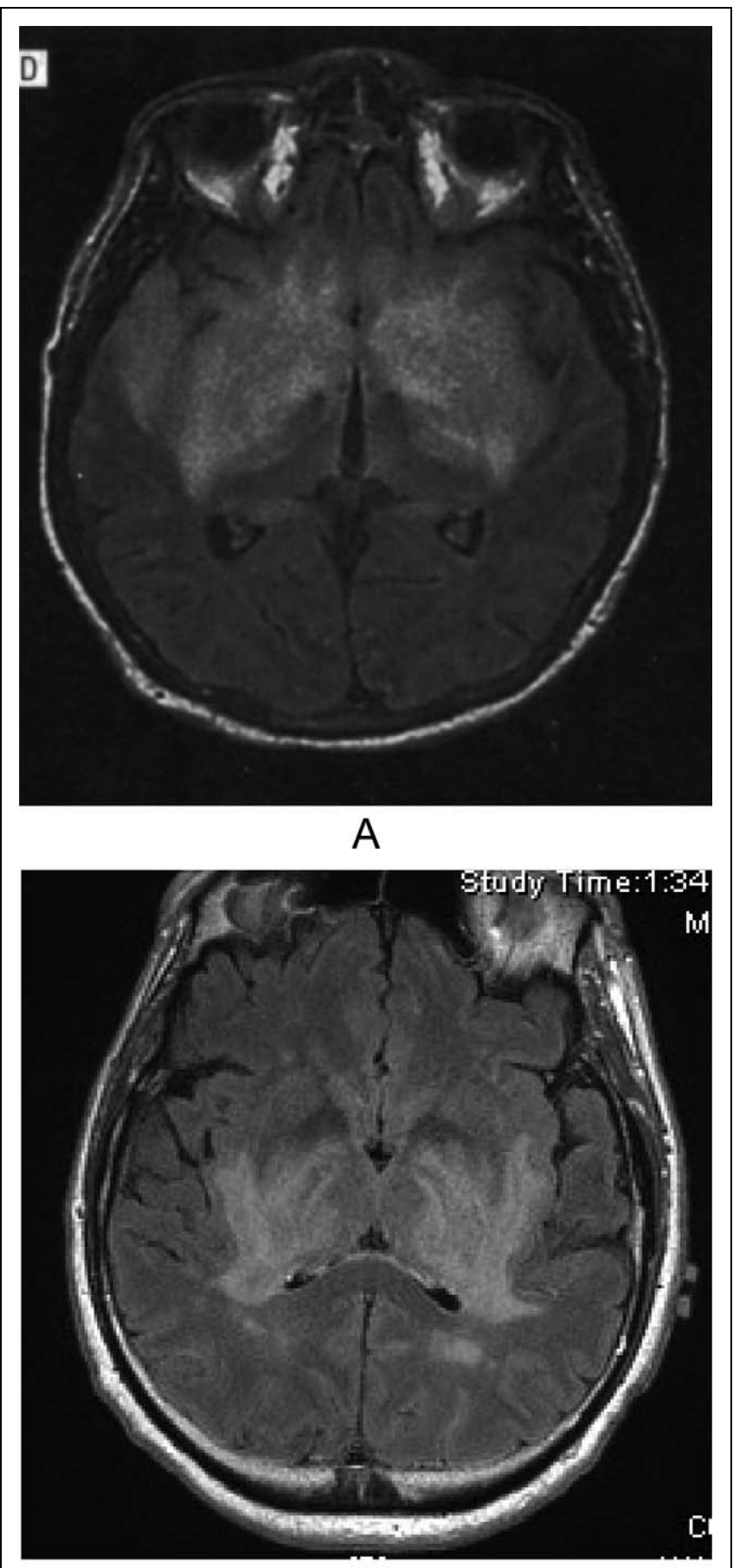

B

Figure 3. Donor-transmitted infections. A, FLAIR MRI shows large areas of signal abnormality in the basal ganglia and temporal lobes in a patient who contracted rabies encephalitis from organ donor. Reprinted with permission from Arch Neurol (2005;62:873-882). ${ }^{13}$ B, FLAIR MRI of a patient with characteristic Flavivirus (West Nile virus) pattern of basal ganglia signal abnormality that also was seen in brain stem (not shown). FLAIR indicates fluid attenuated inversion recovery; MRI, magnetic resonance imaging. immunosuppressive therapy often simultaneously with treatment for an opportunistic infection. ${ }^{36,37}$ Alternatively, an opportunistic infection may manifest itself initially following immune reconstitution, and IRIS can occur in a previously uninfected organ (see case 1 in Figure 4A and B).

Immune reconstitution inflammatory syndrome occurs as a result of shift in dominant $\mathrm{T}$ helper (Th) response from one that restrains inflammation (Th2) to a proinflammatory pattern (Th1). ${ }^{38}$ The resulting inflammatory, often granulomatous, systemic or meningeal reaction, can mimic infection or sarcoidosis. ${ }^{39,40}$ The CNS IRIS, a diagnosis of exclusion, should be considered in patients with previously diagnosed invasive fungal infections tuberculosis, toxoplasmosis, cryptococcosis, CMV, or PML, when the following 3 criteria are met:

1. New appearance of worsening of clinical or radiologic signs of inflammation. Signs can include contrastenhancing leptomeninges or masses, cerebrospinal fluid (CSF) pleocytosis, and physical signs of raised intracranial pressure (ICP; Figure 4C);

2. symptoms occur during receipt of appropriate antimicrobial therapy without evidence of newly acquired infection; and

3 . negative culture results and stable or improved biomarkers for the initial infection. ${ }^{41,42}$

In additional to the same IRIS-related problems seen in the HIV population, SOT recipients face the threat of transplant rejection in the presence of an overly aggressive host inflammatory response. In one analysis of kidney recipients, allografts were lost in $66 \%$ of patients with IRIS compared with $5.9 \%$ of those without IRIS. ${ }^{43}$ Conversely, rejection, a state of heightened inflammatory response, may lead to IRIS in a patient who has a coexisting infection (case 1). When immunosuppression reduction is indicated in the setting of opportunistic infection, reduction in corticosteroids appears to be less risky than discontinuation of calcineurin-inhibitor agents. $^{32}$ Replacement of calcineurin inhibitors with mycophenolate may be associated with greater risk of rejection and graft loss. ${ }^{42,43}$ Similarly, the potency of antifungal regimen may be a risk factor for IRIS as in a reported example of cryptococcal IRIS after replacing fluconazole with voriconazole based on antimicrobial sensitivities. ${ }^{44}$

Corticosteroids remain the most commonly used agents for treatment of active IRIS though there are no controlled studies for CNS-IRIS. ${ }^{45}$ Under investigation as anti-inflammatory adjunctive therapy are both statins, which can inhibit proinflammatory cytokines, and tumor necrosis factor-alpha inhibitors which have some precedent as anti-rejection agents. ${ }^{46-48}$

\section{Posttransplantation Lymphoproliferative Disorder, Lymphoma, and Other Neoplasms}

Posttransplantation lymphoproliferative disorder (PTLD) is a spectrum of disorders from benign polyclonal lymphoid 


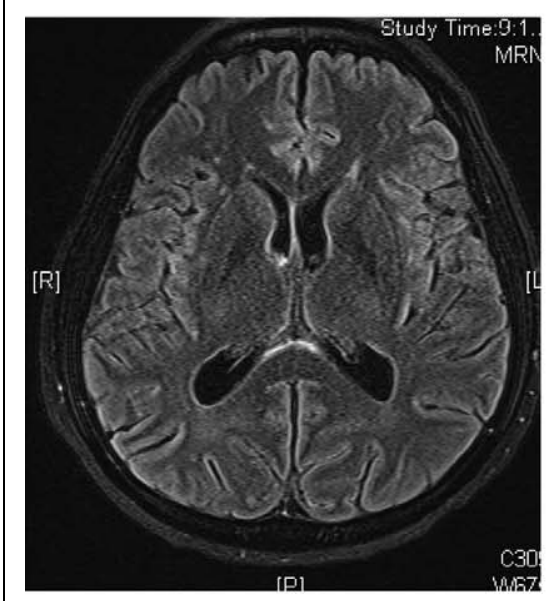

A

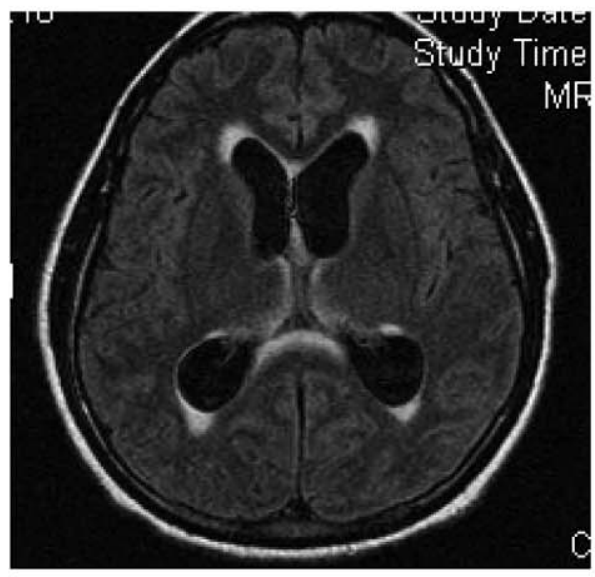

B

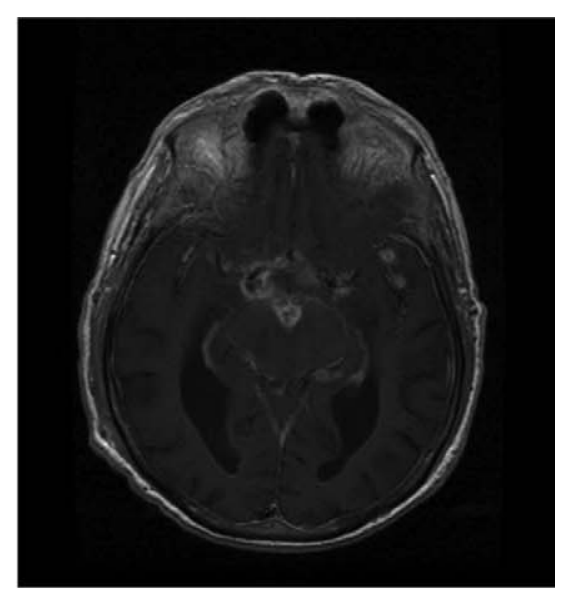

C

Figure 4. Progressive hydrocephalus due to cryptococcosis and IRIS. This case illustrates the difficulty of interpreting host response to a fungal infection in the setting of changing immunosuppressive regimen and organ rejection. Progressive hydrocephalus demonstrated on FLAIR MRI at presentation with headache (A), and 3 months later (B), in a heavily immunosuppressed liver transplant patient with recurrent hepatitis $\mathrm{C}$ and ongoing organ rejection. Gadolinium-enhanced MRI (not shown) showed fluctuating leptomeningeal enhancement. The CSF was abnormal with 84 lymphocytes, glucose $19 \mathrm{mg} / \mathrm{dL}$ and protein 165 to $258 \mathrm{mg} / \mathrm{dL}$. The indolent course, CSF, and negative PCRs and cultures suggested possible lymphoma or neurosarcoidosis. Multiple negative cytologies and meningeal biopsy failed to make a diagnosis until the third lumbar puncture finally revealed cryptococcal meningitis. Antifungal therapy cleared cryptococcal meningitis without worsening what appears to be an example of infection- and rejection-precipitated IRIS. C, Unrelated OLT patient whose gadolinium-enhanced MRI shows multifocal nodular enhancement initially interpreted as recurrent cryptococcal meningitis but ultimately found to be IRIS. Figure 4C reprinted with permission from Liver Transpl (2008; 14:I67I-1674). ${ }^{44}$ FLAIR indicates fluid attenuated inversion recovery; MRI, magnetic resonance imaging; CSF, cerebrospinal fluid; PCR, polymerase chain reaction; IRIS, immune reconstitution inflammatory syndrome; OLT, orthotopic liver transplantation.

hyperplasia to malignant monoclonal $\mathrm{B}(60 \%-70 \%)$ and less often T-cell lymphoma. The PTLD usually involves abdomen, thorax, and solid organ allograft with infrequent CNS involvement. ${ }^{49}$ Clinical syndromes associated with B-cell proliferative clones range from a benign mononucleosis-like picture to fulminant lymphoma with MRI usually demonstrating multiple contrast-enhancing mass lesions. ${ }^{50}$

The risk of systemic lymphoma in the first year post kidney transplant is 20 -fold higher than in the general population but 120 -fold higher in heart transplant recipients. Still higher rates occur in small intestine and dual heart-lung transplant (LT) recipients. ${ }^{51-53}$ The CNS lymphomas represent a small percentage of overall lymphoma but may be especially common after renal transplantation and in patients under 10 and over 60 years of age. The childhood risk is likely related to primary Epstein-Barr virus (EBV) infection in previously seronegative younger patients.

The PTLD results from EBV-induced proliferation of engrafted donor B lymphocytes because of T-cell suppression, but CNS PTLD can occur despite negative serum and spinal fluid EBV DNA PCR. ${ }^{54,55}$ The EBV-negative PTLDs more often occur later than 1 year after SOT. ${ }^{56}$ Biopsy is sometimes necessary to distinguish lymphoma from other infections and when CSF cytology is uninformative immunoglobulin heavy chain gene rearrangement analysis may be helpful. ${ }^{57}$ The mainstay of therapy is reduction of immunosuppression and cytotoxic chemotherapy and rituximab or methotrexate in more aggressive variants, while under development are approaches that involve preemptive management of EBV reactivation with donor-derived EBV-specific T cells. ${ }^{58-60}$

The risk of other secondary malignancies is increased in organ transplant recipients due to reduced immune surveillance and also to activation of oncogenic viruses. Glioblastomas or oligodendrogliomas also have rarely been reported, as have rare cases of primary brain tumor transmission from organ donors to recipients. ${ }^{61,62}$

Drug-related complications. Table 1 in part I of this review details the numerous toxicities of drugs necessary before and after SOT. Drug-related toxicities may cause or mimic any of the above problems including infection, PRES, and metabolic encephalopathy. In addition to the immunophilin ligands (the calcineurin binders cyclosporine and tacrolimus) or FKbinding protein ligands (sirolimus and everolimus), mycophenolate, and glucocorticoids, SOT recipients are treated with mono or polyclonal antibodies such as Muromonab-CD3 (Orthoclone OKT3, Janssen-Cilag, New Brunswick, NJ). Specific neurotoxicities due to OKT3 are lymphocytepredominant meningitis and a diffuse encephalopathy. ${ }^{63}$ The numerous toxicities of tacrolimus include tremor, PRES, seizures, leukoencephalopathy, chronic inflammatory demyelinating polyneuropathy (CIDP), brachial plexitis, optic 


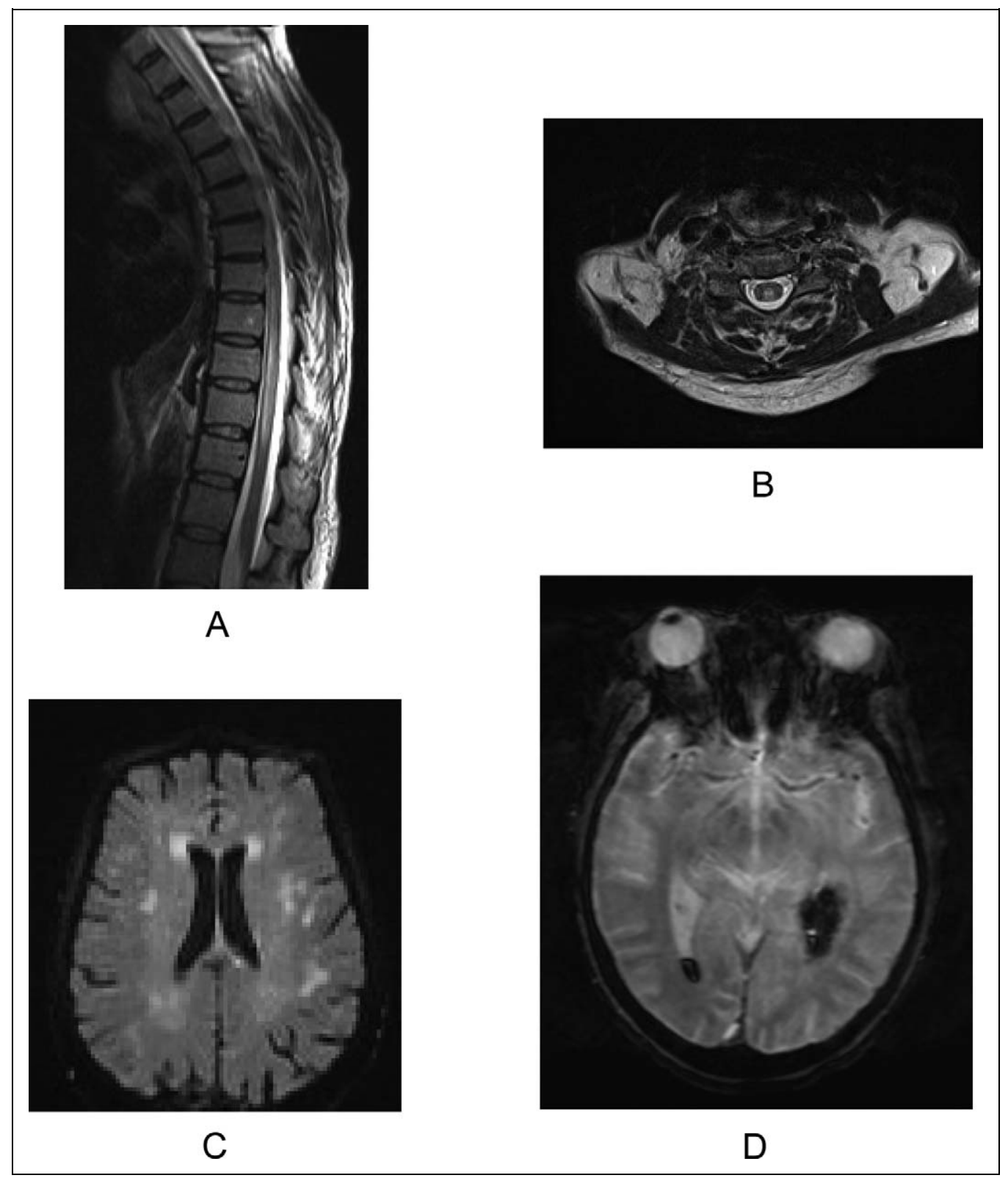

Figure 5. A multifactorial problem. These MRIs demonstrate the diagnostic complexity of a patient 2 years after liver transplant, who presented with diarrhea due to Clostridium difficile and then sudden paraplegia due to extensive transverse myelitis seen on sagittal $(A)$ and axial (B) T2 MRI. The patient also had multiple DWI abnormalities on brain MRI (C) and evidence of intraventricular hemorrhage on gradient echo MRI (D). Tacrolimus level was high on presentation and the patient was found to have CMV in an acellular CSF. Acute myelopathy was ascribed to possible CMV-associated vasculitis, although linking all of the neuroimaging findings pathophysiologically remained difficult. There was no improvement in foscarnet and ganciclovir therapy and the patient ultimately succumbed to Klebsiella sepsis. FLAIR indicates fluid attenuated inversion recovery; MRI, magnetic resonance imaging; DWI, diffusion-weighted imaging; CSF, cerebrospinal fluid; CMV, cytomegalovirus.

neuropathy, hearing loss, seizures, akinetic mutism, central pontine myelinolysis (CPM), and pseudotumor cerebri. ${ }^{64}$ Toxicities are imperfectly correlated with drug level and can occur within the therapeutic range, after just a few doses, or several years after initiation of therapy. Bioavailability is variable because of active secretion of drug into the intestinal lumen by P-glyoprotein (PGP). This excretory mechanism is impaired by diarrhea such as that caused by Clostridium diffficile with destruction of colonic epithelial cells resulting in elevated trough tacrolimus levels ${ }^{65,66}$ (see case 2 in Figure 5).

\section{Complications Specific to the Type of SOT} Liver

Since its introduction more than 45 years ago, OLT has revolutionized the management of its 3 most common indications: 
alcoholic cirrhosis, primary biliary cirrhosis/primary sclerosing cholangitis, and hepatitis $\mathrm{B} / \mathrm{C}{ }^{3}$ The OLT for neoplasia represents less than $5 \%$ of procedures but is used for cholangiocarcinoma, metastases, neuroendocrine tumors, and primary hepatocellular cancers. ${ }^{67}$ Acute liver failure due to acetaminophen overdose adds another group of critically ill patients. Reported incidence of complications varies widely from $4 \%$ to $70 \%$ depending on whether living and cadaveric donors are included or fulminant hepatitis is excluded from analysis. Common complications are hyperammonemic encephalopathy, raised ICP, seizures, stroke (either ischemic or hemorrhagic in the setting of coagulopathy), headache, tremor, osmotic demyelination, and PRES. ${ }^{68}$ Patients receiving living donor transplants have lower neurological complication rates than those receiving a cadaveric graft and patients who have pretransplant hepatic encephalopathy are at higher risk for postoperative neurological complications. ${ }^{69}$ Peak pretransplant serum bilirubin levels and low serum cholesterol helped to predict postoperative neurological transplantations in a large multicenter series that also reported doubling of mortality in patients who sustained neurological complications. In this series, the most recent reported, stroke was the most common OLT complication within the first 30 days. $^{70}$

Several important situations associated with OLT may require input from neurologic consultants:

1. Hepatic myelopathy (HM). The neurologist's role in liver transplantation management may begin before transplantation with assessment of evolving neurological problems that can impact timing of liver transplantation and that will require postoperative management. Hepatic myelopathy is an underrecognized condition of progressive spastic paraparesis in the setting of cirrhosis or portosystemic shunting. While it is not a complication of transplantation, its inclusion here is appropriate because outcomes of patients who have undergone transplantation for HM are encouraging. At present, HM is not recognized as a model for endstage liver disease (MELD) exception for transplatnation, but Caldwell and colleagues recently reported one case from Yale and 15 additional cases from the literature. After OLT there was marked improvement in HM. ${ }^{71}$ Thus, the neurologist may be instrumental in submitting an appeal for an MELD upgrade.

2. Cerebral edema and intracranial hypertension. Elevated ICP occurs in roughly $90 \%$ of patients with grade III/IV encephalopathy. ${ }^{72}$ Medical therapy for intracranial hypertension includes osmotherapy with mannitol or hypertonic saline, control of agitation with midazolam, dexmetetomidine, fentanyl or propofol, and neuromuscular blocking agents. For patients requiring hemodialysis, another way to alleviate ICP is by using hypertonic saline as replacement fluid to adjust serum sodium levels. ${ }^{72}$ Therapeutic hypothermia has been used to treat medically refractory intracranial hypertension preoperatively and intraoperatively 73,74 Hypothermic treatment of refractory postoperative ICP is more problematic and less clearly effective, as in the postoperative setting, detrimental effects of hypothermia include increased infection risks (CMV), blood loss, cardiac arrhythmias, and exacerbation of coagulopathy. ${ }^{75}$

Head computed tomography (CT) is an insensitive measure of cerebral edema, and ICP monitoring is the sole definitive way of diagnosing elevated ICP. Some investigators feel that continuous ICP monitoring and a protocolized response to elevated ICP can improve neurological outcomes. ${ }^{76}$ However, the downside of ICP monitoring is the risk of intracranial hemorrhage and intraventricular monitor placement is not advised for this reason. Adequate reversal of coagulopathy before placement of any device in liver failure patients requires attention to multiple coagulation deficits. Blood products required can include any or all of the following: prothromobin complex concentrates (PCCs), vitamin $\mathrm{K}$, cryoprecipitate, and platelet transfusion. ${ }^{72}$ Debate continues as to whether maintenance of coagulopathy correction is necessary during the entire time the monitor is in place or only during device insertion. ${ }^{76}$ Fiberoptic intraparenchymal monitors, associated with the less than $20 \%$ risk of hemorrhagic complications that many clinicians consider acceptable, are the most frequently used ICP devices in many institutions. ${ }^{77,78}$ An alternative noninvasive method is the pulsatility index measured by transcranial Doppler, which correlates well with ICP fluctuations. ${ }^{79}$ However, transcranial Doppler does not provide direct or continuous measurement of ICP and some investigators feel that it is suboptimally sensitive. ${ }^{80}$

3. Osmotic demyelination, also known as CPM, presents with variable arousal impairment including coma, pseudobulbar affect, and/or cranial nerve palsies. It occurs more often in OLT recipients than in other SOT due to large volume losses and replacements with rapid correction of hyponatremia (Figure 6A). Osmotic demyelination may be extra-pontine as shown in Figure 6B and, thus, is a more accurate term than CPM. Importantly, in the presence of a brain stem syndrome, the consultant also should be wary of PRES, Listeria rhombencephalitis, and, most critically, Wernicke encephalopathy in these often poorly nourished patients. The MRI of Wernicke encephalopathy may be normal or show changes in medial thalami, inferior colliculi, mammillary bodies and in periaqueductal gray. ${ }^{81}$ Impaired or absent verbal and motor responsiveness in the absence of electrolyte abnormalities or seizures also has been reported in OLT recipients and should be considered in the differential of CPM. Drugs associated with the syndrome are tacrolimus, cyclosporine, OKT3, and amphotericin. ${ }^{82-86}$

4. Seizures occur in at least $30 \%$ of fulminant liver failure patients and may complicate the postoperative OLT period $^{72}$. The diverse seizure etiologies include hypoglycemia, hyponatremia, uremia, calcineurin inhibitors, PRES, intracranial hemorrhage, mitochondrial dysfunction due to acute hyperammonemia, and the acute $\gamma$-aminobutyric 


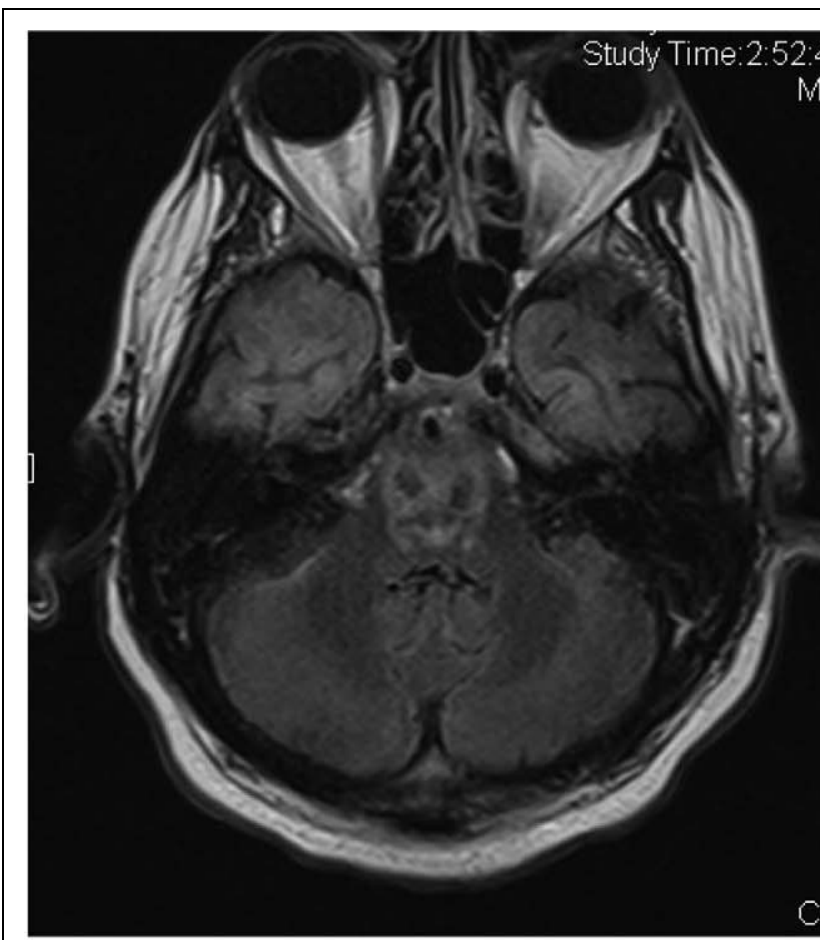

A

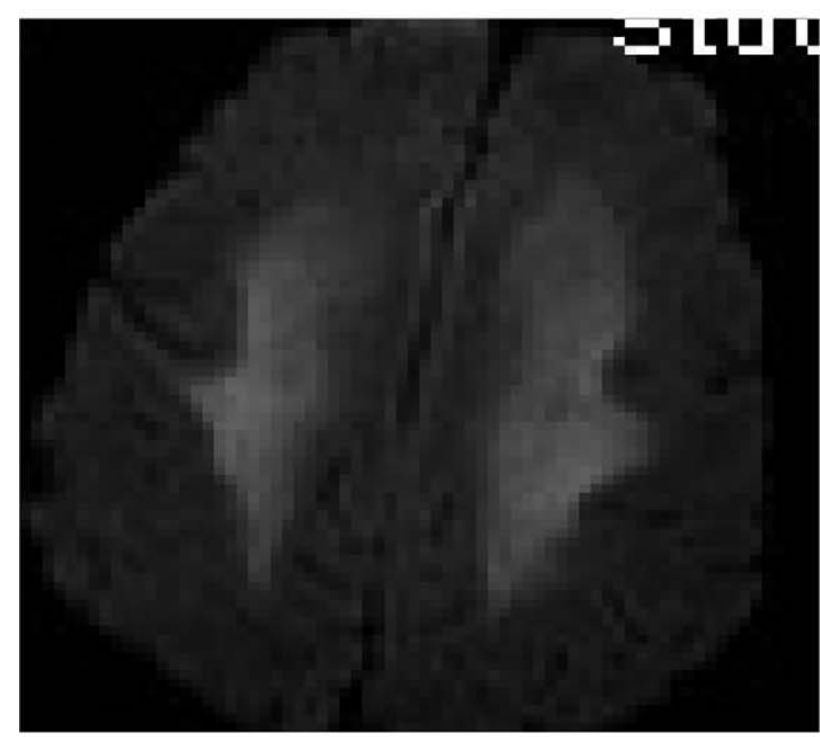

B

Figure 6. Osmotic demyelination. A, FLAIR MRI of a patient post liver transplant with clinical signs of dysarthria, dysphagia, and abducens palsies after rapid correction of hyponatremia. B, DWI MRI of a renal failure patient pretransplantation with osmotic demyelination demonstrating that extrapontine sites can be involved, often after recent hemodialysis. FLAIR indicates fluid attenuated inversion recovery; DWI, diffusion-weighted imaging; $\mathrm{MRI}$, magnetic resonance imaging.

acid (GABA)ergic withdrawal state associated with the posttransplantation period. $^{87}$ Distinguishing transient metabolic or drug-related seizures, particularly those due to tacrolimus or cyclosporine (see Table I in the first part of this review), from PRES, vascular or infectious etiologies often requires neuroimaging and at times lumbar puncture. Tacrolimus or cyclosporine levels should be checked, though seizures can occur with therapeutic levels. Electroencephalogram (EEG) plays a useful role in several settings to (a) differentiate clinically ambiguous tremor and myoclonus from ictal activity, (b) disclose nonconvusive seizures; or (c) reveal triphasic waves indicative of metabolic encephalopathy. Since many patients may have subclinical seizure activity, long-term continuous monitoring is recommended for all grade III/IV hepatic encephalopathy and suboptimally responsive transplant patients to detect treatable seizures. ${ }^{88,89}$ Electrically documented seizure activity should be treated. Levetiracetam has been suggested as a drug that can be loaded rapidly and that does not induce hepatic enzymes that can alter immunosuppressant levels. ${ }^{90}$

5. Hearing loss. New hearing impairment posttransplantation was reported by $27 \%$ of OLT patients surveyed by questionnaire in a single-center German study. In almost half of the patients hearing impairment began within 2 years of OLT and was positively associated with tacrolimus use. The authors invoke possible tacrolimus vascular or neurotoxicity and note that switching immunosuppressants may help improve hearing. ${ }^{91}$ Also reported is sudden hearing loss and tinnitus associated with a normal tacrolimus blood level with rapid improvement after discontinuation of tacrolimus. $^{92}$

\section{Kidney}

Common indications for renal transplantation include kidney failure due to diabetes, glomerulonephritis, hypertension, polycystic kidney disease, and cancer therapy-related nephrotoxicity, each of which poses potential neurological problems independent of the transplantation procedure. ${ }^{3}$ While hypertension-related stroke is a frequent peritransplant problem as it is with other SOT procedures, neurological complications specific to renal transplantation include potential femoral or lumbosacral plexus nerve injury, hypertension-related stroke, and uremic encephalopathy. While the risk of systemic lymphoma in renal transplant recipients is lower than that in other SOT, when lymphoma does occur, CNS involvement appears to be higher. ${ }^{53}$ The risk of melanoma is roughly 3.6 times that of general population, with the highest risk in patients who experienced at least one acute rejection episode. ${ }^{93}$ The high risk of CNS metastases with this primary tumor should prompt biopsy of suspicious skin lesions.

A particular concern with renal insufficiency is the syndrome of nephrogenic systemic fibrosis (NSF) following administration of gadolinium-based contrast agents (GBCAs). This progressive infiltration of skin and other organs by a fibrotic process has been reported to occur with a mean interval of 29 
days after GBCA use, with most cases occurring between 2 and 3 months after exposure. However, there is a very wide range (4-112 days). ${ }^{94}$ The incidence of NSF has been reduced dramatically by the institution of guidelines restricting GBCA use (without planned postcontrast dialysis) to patients with glomerular filtration rate exceeding $30 \mathrm{~mL} / \mathrm{min} .{ }^{95}$ However, the wide range of time interval after GBCA means that a patient could present with the problem well after the postoperative period as illustrated by a recent report of a renal transplant patient who had also received high doses of erythropoietin and had last received GBCA 8 months previously. ${ }^{96}$

\section{Heart}

Neurological complications in heart transplant patients often reflect prior cardiovascular and CNS status. Ischemic stroke is the most common serious neurological complication after heart transplantation occurring in up to $10 \%$ of patients. ${ }^{97}$ Intracranial hemorrhage is less common. Since the incidence of PRES is as high as $6 \%$ in SOT recipients and since PRES can be complicated by status epilepticus or by hemorrhage, it must be distinguished by diffusion weighted imaging, apparent diffusion coefficient sequences, and/or perfusion MRI sequences from other causes of stroke in this population. ${ }^{98-100}$

Among SOT recipients, heart transplant patients have the highest incidence of toxoplasmosis, as the parasitic cysts can be found in myocardium. ${ }^{97}$ This infection usually occurs within 3 months after transplantation, and CNS involvement is common. The MRI typically shows multiple ringenhancing lesions. Demonstration of the parasite in blood provides additional diagnostic support as does response to pyrimethamine/sulfadiazine. Failure to respond rapidly to antimicrobial therapy leads to consideration of other causes of multifocal mass lesions such as lymphoma.

\section{Lung}

The LT recipients have the highest mortality rates of all SOT recipients, rates that are further increased in nearly one-third of such patients who experience a serious neurological complication. ${ }^{101}$ The most common pulmonary indications for transplantation are chronic obstructive pulmonary disease, alpha-1 antitrypsin deficiency, and primary pulmonary hypertension. ${ }^{3}$ In the largest series to date from the Mayo Clinic, the most frequent reasons for in-hospital neurologic consultation were perioperative stroke, severe multifactorial encephalopathy, and critical illness polyneuropathy, or myopathy. In this series, LT patients also experienced disorders specific to LT that placed them at risk for neurologic complications. ${ }^{101}$ For example, LT patients who required intensive immunosuppressive treatment with anti-B cell rituximab therapy for the humorally mediated lung rejection syndrome capillaritis were at risk for unusually severe courses of WNV infection with neuroinvasive disease. ${ }^{102}$

\section{Intestinal and Multivisceral Transplantation}

Indications for intestinal transplantation include short-bowl syndrome caused by mesenteric thrombosis or by prior resections for Crohn disease or neoplasm. ${ }^{3}$ Malnutrition, metabolic derangements after prolonged total parenteral nutrition, and hepatic dysfunction often accompany these conditions. Radiation therapy for prior neoplasm may complicate abdominal wound healing. All these issues may contribute to a rate of neurological complications postoperatively that exceeds that of liver and heart transplant patients. Heavy immune suppression is required to suppress intestinal rejection, putting patients at risk for early invasive fungal infections such as Aspergillus and leading to a heavy intestinal bacterial load. Rejection and sepsis are closely linked as rejection-associated intestinal barrier damage may cause sepsis from bacterial translocation. ${ }^{103}$

\section{The Evolving Spectrum of Late Sequelae of SOT}

With 1-year survival now exceeding $80 \%$ in all types of SOT and 5 -year survival over $50 \%$, the hospitalist is increasingly confronted with patients long removed from the initial procedure but also immunologically altered for prolonged periods. ${ }^{32}$ Novel differential diagnostic dilemmas are posed by SOT patients who remain at risk for infection, particularly invasive fungal infection. ${ }^{104-106}$ The complex balance of immune modulatory medical regimens of SOT recipients leads to unusual situations such as the recently described case of autoimmune anti-N-methylD-aspartate receptor (NMDAR) encephalitis developing in a renal transplant patient while the patient was receiving mycophenolate and tacrolimus. ${ }^{107}$ Immunological sequelae of altered suppressive or antibiotic regimens may put the transplanted organ at risk. ${ }^{36,37}$ As patients resume their normal lives including travel and zoonotic exposures, the diagnostic acumen of the hospitalist will have to expand to adapt to emerging infections. ${ }^{108}$

Cases 1 and 2 in Figures 4 and 5 illustrate differential diagnostic dilemmas of atypical disease presentation in immunocompromised SOT patients, serving as examples of several of the themes of this review. Figure 4 shows progressive communicating hydrocephalus on MRI in an OLT patient whose CSF formula suggested infection, lymphoma, or sarcoidosis, all possible diagnoses in a patient more than 1 year after OLT with recurrent hepatitis C. One would expect increased virulence of an infectious pathogen in a heavily immunocompromised patient. In fact, this was an exceedingly indolent presentation of cryptococcosis evolving over several months and emerging as meningitis only in the context of the heightened inflammation of organ rejection. Figure 5 illustrates another OLT patient, also more than 1 year after LT, with an elevated tacrolimus level on admission with associated Clostridium difficile diarrhea. The patient experienced acute transverse myelitis and an acute disseminated encephalomyelitis (ADEM)-like picture with cerebral and intraventricular hemorrhage. The initial consideration was that all the clinical symptoms fit with tacrolimus toxicity. 
However, the patient had a positive CSF PCR for CMV. The interplay of tacrolimus and the potential reactivation of $\mathrm{CMV}$ as the cause for this ultimately fatal syndrome remains poorly understood but underscores the need to search for multifactorial etiologies.

\section{Conclusions}

Costly transplantation procedures have produced many sustained remissions offering the best chance for cure for many patients. However, long-term consequences include an increased risk of secondary malignancy, cognitive and psychosocial issues, vascular problems, and endocrine abnormalities. Future studies will determine the least toxic regimens for specific conditions to reduce the severity and incidence of potentially devastating neurological complications. Better treatments for specific infections like PML are needed. Even more crucial are fundamental developments like bioengineering of embryonic stem cells that might altogether eliminate the need for human leucocyte antigen (HLA) typing and preparative therapy and, it could be hoped, might greatly reduce both systemic and neurological morbidity and mortality associated with transplantation. Until then, the hospitalist can make a significant contribution by striking preemptively to anticipate infections and reacting expeditiously to minimize adverse consequences of neurological complications while advising on a host of acronymic complications (PRES, drug reaction (or rash) with eosinophilia and systemic symptoms, IRIS, PML, graft versus host disease, posttransplant acute limbic encephalitis, PTLD, to name but a few), thereby improving both survival and quality of life for these vulnerable patients.

\section{Acknowledgments}

The authors gratefully acknowledge helpful discussions with Dr Joshua Levine about choice of intracranial pressure monitoring devices for liver transplant patients.

\section{Declaration of Conflicting Interests}

The authors declared no potential conflicts of interest with respect to the research, authorship, and/or publication of this article.

\section{Funding}

The authors received no financial support for the research, authorship, and/or publication of this article.

\section{References}

1. Organ Procurement and Transplantation Network. http://optn. transplant.hrsa.gov. Accessed March 24, 2012.

2. Senzolo M, Ferronato C, Burra P. Neurologic complications after solid organ transplantation. Transpl Int. 2009;22(3):269-278.

3. Dhar R, Human T. Central nervous system complications after transplantation. Neurol Clin, 2011;29(4):943-972.

4. Pustavoitau A, Bhardwaj A, Stevens R. Neurological complications of transplantation. J Intensive Care Med. 2011;26(4): 209-222.
5. Sharma P, Eesa M, Scott JN. Toxic and acquired metabolic encephalopathies: MRI appearance. AJR Am J Roentgenol. 2009; 193(3):879-886.

6. Bindu PS, Sinha S, Taly AB, Christopher R, Kovoor JM. Cranial MRI in acute hyperammonemic encephalopathy. Pediatr Neurol. 2009;41(2):139-142.

7. Schiff D, Lopes MB, Neuropathological correlates of reversible posterior leukoencephalopathy. Neurocrit Care. 2005;2(3): 303-305.

8. Horbinski C, Bartynski WS, Carson-Walter E, et al. Reversible encephalopathy after cardiac transplantation: histologic evidence of endothelial activation, T-cell specific trafficking and vascular endothelial growth factor expression. AJNR Am J Neuroradiol. 2009;30(3):588-590.

9. Srinivasan A, Burton EC, Kuehnert MJ, et al. Transmission of rabies virus from an organ donor to four transplant recipients. N Engl J Med. 2005;352(11):1103-1111.

10. Shaz BH. Transfusion transmitted diseases. In: Hilyer CD, Shaz BH, Zimring JG, Abshire TC, eds. Transfusion Medicine and Hemostasis: Clinical and Laboratory Aspects. New York, NY: Elsevier; 2009:361-371.

11. Iwamoto M, Jernigan DB, Guasch A, et al. Transmission of West Nile virus from an organ donor to four transplant recipients. N Engl J Med. 2003;348(22):2196-2203.

12. Fischer SA, Graham MB, Kuehnert MJ, et al. Transmission of lymphocytic choriomeningitis virus by organ transplantation. N Engl J Med. 2006;354(21):2235-2249.

13. Burton EC, Burns DK, Opatowsky MJ, et al. Rabies encephalomyelitis: clinical, neuroradiological, and pathological findings in 4 transplant recipients. Arch Neurol. 2005;62(6):873-882.

14. Orozco L, Hanigan WH, Khan M, et al. Neurosurgical intervention in the diagnosis and treatment of Balamuthia mandrillaris encephalitis. J Neurosurg. 2011;115(3):636-640.

15. Sun HY, Wagener MM, Singh N. Cryptococcosis in solid-organ, hematopoietic stem cell, and tissue transplant recipients: evidence-based evolving trends. Clin Infect Dis. 2009;48(11): 1566-1576.

16. Baddley JW, Schain DC, Gupte AA, et al. Transmission of cryptococcus neoformans by organ transplantation. Clin Infect Dis. 2011;52(4):e94-e98.

17. Fishman JA, Greenwald MA, Grossi PA. Transmission of infection with human allografts: essential considerations in donor screening. Clin Infect Dis. 2012;55(5):720-727.

18. Soyama A, Eguchi S, Takatsuki M, et al. Human T-cell leukemia virus type 1-associated myelopathy following living donor liver transplant. Liver Transpl. 2008;14(5):647-650.

19. Safdar N, Smith J, Knasinski V, et al. Infections after the use of alemtuzumab in SOT recipients: a comparative study. Diagn Microbiol Infect Dis. 2010;66(1):7-15.

20. Peleg AY, Husain S, Kwak EJ, et al. Opportunistic infections in 547 organ transplant recipients receiving alemtuzumab, a humanized monoclonal CD-52 antibody. Clin Infect Dis. 2007;44(2):204-212.

21. Marcen R. Immunosuppressive drugs in kidney transplantation. Impact on patient survival and incidence of cardiovascular disease, malignancy, and infection. Drugs. 2009;69(16):2227-2243. 
22. Nishida H, Ishida H, Tanaka T, et al. Cytomegalovirus infection following renal transplantation in patients administered low-dose rituximab induction therapy. Transpl Int. 2009;22(10):961-969.

23. Kamar N, Milioto O, Puissant-Lubrano B, et al. Incidence and predictive factors for infectious disease after rituximab therapy in kidney-transplant patients. Am J Transplant. 2010;10(1):89-98.

24. Yehia B, Davison A, Sisson S. Transplant troubles. Am J Med. 2009;122(7):629-631.

25. Mateen FJ, Muralidharan R, Carone M, et al. Progressive multifocal leukoencephalopathy in transplant recipients. Ann Neurol. 2011;70(2):305-322.

26. Manfro RC, Vedolin L, Cantarelli M, et al. Progressive multifocal leukoencephalopathy in a kidney transplant recipient after conversion to mycophenolic acid therapy. Transpl Infect Dis. 2009;11(2):189-190.

27. Mueller NJ. New immunosuppressive strategies and the risk of infection. Transpl Infect Dis. 2008;10(6):379-384.

28. Neff RT, Hurst FP, Falta EM, et al. Progressive multifocal leukoencephalopathy and use of mycophenolate mofetil after kidney transplantation. Transplantation. 2008;86(10): 1474-1478.

29. Singh N, Dromer F, Perfect JR, Lortholary O. Cryptococcosis in solid organ transplant recipients: current state of the science. Clin Infect Dis. 2009;47(10):1321-1327.

30. Singh N, Lortholary O, Dromer F, et al. Central nervous system cryptococcis in solid organ transplant recipients: clinical relevance of abnormal neuroimaging findings. Transplantation. 2008;86(5):647-651.

31. Sun HY, Wagener MM, Singh N. Cryptococcosis in solid-organ, hematopoietic stem cell and tissue transplant recipients: evidence-based evolving trends. Clin Infec Dis. 2009;48(11): 1566-1576.

32. Singh N. How I treat cryptococcosis in organ transplant recipients. Transplantation. 2012;93(1):17-21.

33. Kontoyiannis DP, Lewis RE, Alexander BD, et al. Calcineurin inhibitor agents interact synergistically with antifungal agents in vitro against Cryptococcus neoformans isolates: correlation with outcome in solid organ transplant recipients with cryptococcosis. Antimicrob Agents Chemother, 2008;52(2):735-738.

34. Silveira FP, Husain S, Kwak EJ, et al. Cryptococcosis in liver and kidney transplant recipients receiving anti-thymocyte globulin or alemtuzumab. Transplant Infect Dis. 2007;9(1):22-27.

35. Shelburne SA 3rd, , Hamill RJ, Rodriguez-Barradas MC, et al Immune reconstitution inflammatory syndrome: emergence of a unique syndrome during highly active antiretroviral therapy. Medicine. 2002;81(3):213-227.

36. Perfect JR. The impact of the host on fungal infections. Am J Med. 2012;125(suppl 1):S39-S51.

37. Sun HY, Singh N. Oppportunistic infection-associated immune reconstitution syndrome in transplant recipients. Clin Infect Dis. 2011;53(2):168-176.

38. Singh N. Novel immune regulatory pathways and their role in immune reconstitution syndrome in organ transplant recipients with invasive mycoses. Eur J Clin Microbiol Infect Dis. 2008; 27(6):403-408.
39. Singh N, Lortholaray O, Alexander BD, et al. An immune reconstitution syndrome-like illness associated with Cryptococcus neoformans infection in organ transplant recipients. Clin Infect Dis. 2005;40(12):1756-1761.

40. Johnson T, Nath A. Immune reconstitution inflammatory syndrome and the central nervous system. Curr Opin Neurol. 2011;24(3):284-290.

41. Legris T, Massad M, Purgus R, et al. Immune reconstitution inflammatory syndrome mimicking relapsing cryptococcal meningitis in a renal transplant recipient. Transplant Infect Dis. 2011;13(3):303-308.

42. Singh N, Perfect JR. Immune reconstitution syndrome associated with opportunistic mycoses. Lancet Infect Dis. 2007;7(6):395-401.

43. Singh N, Lortholary O, Alexander BD, et al. Allograft loss in renal transplant recipients with Cryptococcus neoformans associated immune reconstitution syndrome. Transplantation. 2005;80(8):1131-1133.

44. Crespo G, Cervera C, Michelena J, et al. IRIS after voriconazole treatment for cyrptococcal meningitis in a liver transplant recipient. Liver Transpl. 2008;14(11):1671-1674.

45. McCarthy M, Nath A. Neurologic consequences of the immune reconstitution inflammatory syndrome (IRIS). Curr Neurol Neurosci Rep. 2010;10(6):467-475.

46. Sitapati AM, Kao Cl, Cachay ER, et al. Treatment of HIVrelated inflammatory cerebral cryptococcoma with adalimumab. Clin Infect Dis. 2010;50(2):e7-e10.

47. Broady RK, Levings MK. Graft-versus-host disease: suppression by statins. Nat Med. 2008;14(11):1155-1156.

48. Gerlach UA, Koch M, Muller HP, et al. Tumor necrosis factor alpha inhibitors as immunomodulatory antirejection agents after intestinal transplantation. Am J Transplant. 2011;11(5):1041-1050.

49. Knight J, Tsodikov A, Cibrik D, et al. Lymphoma after solid organ transplantation: risk, response to therapy, and survival at a transplantation center. J Clin Oncol. 2009;27(20):1-19.

50. Buell JF, Gross TG, Hanaway MJ, et al. Posttransplant lymphoproliferative disorder: significance of central nervous system involvement. Transplant Proc. 2005;37(2):954-955.

51. Cavaliere R, Petroni G, Lopes MB, et al. Primary central nervous system post-transplantation lymphoproliferative disorder: an International Primary Central Nervous System Lymphoma Collaborative Group Report. Cancer. 2010; 116(4):863-870.

52. Castellano-Sanchez AA, Li S, Qian J, Lagoo A, Weir E, Brat DJ. Primary central nervous system posttransplant lymphoproliferative disorders. Am J Clin Pathol. 2004;121(2):246-253.

53. Evens AM, Roy R, Sterrenberg D, et al. Post-transplantation lymphoproliferative disorders: diagnosis, prognosis, and current approaches to therapy. Curr Oncol Rep. 2010;12(6):383-394.

54. Opelz G, Dohler B. Lymphomas after solid organ transplantation: a collaborative transplant study report. Am J Transplant. 2004;4(2):222-230.

55. Gottschalk S, Rooney CM, Hesplo HE. Post-transplantation lymphoproliferative disorders. Annu Rev Med. 2005;56:29-44.

56. Hamadani M, Martin LK, Benson DM, et al. Central nervous system post-transplant lymphoproliferative disorder despite 
negative serum and spinal fluid Epstein-Barr virus DNA PCR. Bone Marrow Transplant. 2007;39(4):249-251.

57. Baehring JM, Landry ML, Cooper D, et al. CSF IgH gene arrangement analysis in isolated post-transplant lymphoproliferative disorder of the central nervous system. J Neurooncol. 2008;86(1):57-60.

58. Nabors LB, Palmer CA, Julian BA, Przekwas AM, Kew CE. Isolated central nervous system posttransplant lymphoproliferative disorder treated with high-dose intravenous methotrexate. Am J Transplant. 2009;9(5):1243-1248.

59. Ahmad I, Cau NV, Kwan J, et al. Preemptive management of Epstein-Barr virus reactivation after hematopoietic stem-cell transplantation. Transplantation. 2009;87(8):1240-1245.

60. Evens AM, David KA, Helenowski I, et al. Multicenter analysis of 80 solid organ transplantation recipients with post-transplantation lymphoproliferative disease: outcomes and prognostic factors in the modern era. J Clin Oncol. 2010;28(6):1038-1046.

61. Schiff D, O'Neill B, Wijdicks E, Antin JH, Wen PY. Gliomas arising in organ transplant recipients: an unrecognized complication of transplantation? Neurology. 2001;57(8):1486-1488.

62. Fatt MA, Horton Km, Fishman EK. Transmission of metastatic glioblastoma multiforme from donor to lung transplant recipient. J Comput Assist Tomogr, 2008;32(3):407-409.

63. Parizel PM, Snoeck HW, van den Hauwe L, et al. Cerebral complications of murine monoclonal CD3 antibody (OKT3): CTand MR findings. Am J Neuroradiol. 1997;18(10):1935-1938.

64. Balu R, Pruitt AA. Neurologic complications of immunosuppressive drugs. In: Wen OPY, Schiff D, Quant Lee E, eds. Neurologic Complications of Cancer Therapy. New York, NY: Demos Medical; 2012:107-124.

65. Asano T, Nishimoto K, Hayakawa M. Increased tacrolimus trough levels in association with severe diarrhea. Transplant Proc. 2004;36(7):2096-2097.

66. Lemahieu W, Maes B, Verbeke K, et al. Cytochrome P450 3A4 and P-glycoprotein activity and assimilation of tacrolimus in transplant patients with persistent diarrhea. Am J Tansplant, 2005;5(6):1383-1391.

67. Wolfe RA, Roys EC, Merion RM. Trends in organ donation and transplantation in the United States 1999-2008. Am J Transplant. 2010;10(4 pt 2):961-972.

68. Dhar R, Young GB, Marotta P. Perioperative neurological complications after liver transplantation are best predicted by pre-transplant hepatic encephalopathy. Neurocrit Care. 2008; 8(2):253-258.

69. Lewis MB, Howdle PD. Neurologic complications of liver transplantation in adults. Neurology .2003;61(9):1174-1178.

70. Vizzini G, Asaro M, Miraglia R, et al. Changing picture of central nervous system complications in liver transplant recipients. Liver Transpl. 2011;17(11):1279-1285.

71. Caldwell C, Werdiger N, Jakab S, et al. Use of model for endstage liver disease exception points for early liver transplantation and successful reversal of hepatic myelopathy with a review of the literature. Liver Transplant. 2010;16(7):818-826.

72. Frontera JA, Kalb T. Neurological management of fulminant heaptic failure. Neurocrit Care. 2011;14(2):318-327.
73. Jalan R, Olde Damink SW, Deutz NE, et al. Moderate hypothermia prevents cerebral hyperemia and increase in intracranial pressure in patients undergoing liver transplantation for acute liver failure. Transplantation. 2003;75(12):2034-2039.

74. Mpabanzi L, Jalan R, Neurological complications of acute liver failure: pathophysiological basis of current management and emerging therapies. Neurochem Int. 2012;60(7):736-742.

75. Holena DN, Tolstoy NS, Mills AM, Fox AD, Levine JM. Therapeutic hypothermia for treatment of intractable intracranial hypertension after liver transplantation. Am J Crit Care. 2012; 21(1):71-74.

76. Raschke RA, Curry SC, Rempe S, et al. Results of a protocol for the management of patients with fulminant liver failure. Crit Care Med. 2008;36(8):2244-2248.

77. Straavitz RT, Kramer AH, Davern T, et al. Intensive care of patients with acute liver failure: recommendations of the US Acute Liver Failure Study Group. Crit Care Med. 2007; 35(11):2498-2508.

78. Fernandes HM, Bingham K, Chambers IR, et al. Clinical evaluation of the Codman microsensor intracranial pressure monitoring system. Acta Nerochir Suppl. 1998;71:44-46.

79. Bellner J, Romner B, Reinstrup P, et al. Transcranial doppler sonography pulsatility index (PI) reflects intracranial pressure (ICP). Surg Neurol. 2004;62(1):45-51.

80. Figaji AA, Zwane E, Fieggen AG, Siesjo P, Peter JC. Transcranial Doppler pulsatility index is not a reliable indicator of intracranial pressure in children with severe traumatic brain injury. Surg Neurol. 2009;72(4):389-394.

81. Shin NY, Nam HS, Lee SK. Hemorrhagic Wernicke's encephalopathy in a patient with liver transplantation. Neurology. 2009; 73(17): 1423.

82. Sierra-Hidalgo F, Martinez-Salio A, Moreno-Garcia S, et al. Akinetic mutism induced by tacrolimus. Clin Neuropharmacol. 2009;32(5):293-294.

83. Walker RW, Rosenblum MK. Amphotericin B-associated leukoencephalopathy. Neurology. 1992;42(10):2005-2010.

84. Pittock SJ, Rabinstein AA, Edwards BS, Wijdicks EF. OKT3 neurotoxicity presenting as akinetic mutism. Transplantation, 2003;75(7):1058-1060.

85. Bianco F, Fattapposta F, Locuratolo N, et al. Reversible diffusion MRI abnormalities and transient mutism after liver transplantation. Neurology. 2004;62(6):981-983.

86. Wijdicks EF, Wiesner RH, Kroma RA. Neurotoxicity in liver transplant recipients with cyclosporine immunosuppression. Neurology. 1995;45(11):1962-1964.

87. Ellis AJ, Wendon JA, Williams R. Subclinical seizure activity and prophylactic phenytoin infusion in acute liver failure: a controlled clinical trial. Hepatology. 2000;32(3):536-541.

88. Claassen J, Mayer SA, Kowalski RG, Emerson RG, Hirsch LJ. Detection of electrographic seizures with continuous EEG monitoring in critically ill patients. Neurology. 2004;62(10): 1743-1748.

89. Oddo M, Carrera E, Claassen J, Mayer SA, Hirsch LJ. Continuous electroencephalography in the medical intensvie care unit. Crit Care Med, 2009;37(6):2051-2056. 
90. Glass GA, Stankiewicz J, Mithoefer A, Freeman R, Bergethon PR. Levetiracetam for seizures after liver transplantation. Neurology. 2005;64(6):1084-1085.

91. Rifai K, Kirchner GI, Bhr MJ, et al. A new side effect of immunosuppression: High incidence of hearing impairment after liver transplantation. Liver Transplant. 2006;12(3):411-415.

92. Norman K, Bonatti H, Dickson RC, Aranda-Michel J. Sudden hearing loss associated with tacrolimus in a liver transplant recipient. Eur Soc Organ Transplant. 2006;19(7):601-603.

93. Hollenbeak CS, Todd M, Billingsley EM, et al. Increased incidence of melanoma in renal transplantation recipients. Cancer. 2005;104(9):1962-1967.

94. Perez- Rodriguez J, Lai S, Ehst BD, Fine DM, Bluemke DA. Nephrogenic systemic fibrosis: incidence, associations, and effect of risk factor assessment: Report of 33 cases. Radiology. 2009;250(2):371-377.

95. Wang Y, Alkasab TK, Narin O, et al. Incidence of nephrogenic systemic fibrosis after adoption of restrictive gadolinium-based contrast agent guidelines. Radiology. 2011;260(1):105-111.

96. Hashemi P, Sina B, Rietkirk W, Safai B. The debate between gadolinium versus erythropoietin in a renal transplant patient with nephrogenic systemic fibrosis. J Nephrol. 2012.

97. Munoz P, Valerio M, Palomo J, et al. Infectious and noninfectious neurologic complications in heart transplant recipients. Medicine (Baltimore). 2010;89(3):166-175.

98. Kozak OS, Wijdicks EF, Manno EM, et al. Status epilepticus as initial manifestation of posterior reversible encephalopathy syndrome. Neurology. 2007;69(9):894-897.

99. Aranas RM, Prabhakaran S, Lee VH. Posterior reversible encephalopathy syndrome associated with hemorrhage. Neurocrit Care. 2009;10(3):306-312.
100. Hefzy HM, Bartyski WS, Bordman JF, Lacomis D. Hemorrhage in posterior reversible encephalopathy syndrome: imaging and clinical features. AJNR Am J Neuroradiol. 2009; 30(7):1371-1379.

101. Mateen FJ, Dierkhising RA, Rabinstein AA, van de Beek D, Wijdicks EF. Neurological complications following adult lung transplantation. Am J Transplant. 2010;10(4):908-914.

102. Levi ME, Quan D, Ho JT, et al. Impact of rituximab-associated Bcell defects on West Nile virus meningoencephalitis in solid organ transplant recipients. Clin Transplant. 2010;24(2):223-228.

103. Zivković SA, Eidelman BH, Bond G, Costa G, Abu-Elmagd $\mathrm{KM}$. The clinical spectrum of neurologic disorders after intestinal and multivisceral transplantation. Clin Transplant. 2010; 24(2):164-168.

104. Ruping MJ, Vehreschild JJ, Cornely OA. Patients at high risk of invasive fungal infections: when and how to treat. Drugs. 2008; 68(14):1941-1962.

105. Maertens J, Theunissen K, Verhoef G, et al. Galactomannan and computed tomography-based preemptive antifungal therapy in neutropenic patients at high risk for invasive fungal infection: a prospective feasibility study. Clin Infect Dis. 2005;41(9):1242-1250.

106. Seton M, Pless M, Fishman JA, Caruso PA, Hedley-Whyte ET. Case records of the Massachusetts General Hospital. Case 182008. A 68-year-old man with headache and visual changes after liver transplantation. N Engl J Med. 2008;358(24):2619-2628.

107. Zhao CZ, Erickson J, Dalmau J. Clinical reasoning: agitation and psychosis in a patient after renal transplantation. Neurology, 2012;79(5):e41-e44.

108. Kotton CN. Zoonoses in solid-organ and hematopoietic stem cell transplant recipients. Clin Infect Dis. 2007;44(6):857-866. 